\title{
El socialismo cubano y el culto a la personalidad
}

\section{Cuban socialism and personality cult}

\author{
Abner Barrera Rivera \\ Instituto de Estudios Latinoamericanos (IDELA) \\ Universidad Nacional, Costa Rica \\ dan.barrera.rivera@una.cr
}

\begin{abstract}
Resumen
Desde el triunfo de la Revolución Cubana en 1959, sus adversarios desarrollaron una gran industria literaria (artículos, libros y vídeos) con el objetivo de atacarla, agredirla y difamarla; entre las acusaciones que hicieron estaba que, en Cuba, se promovía el culto a la personalidad de Fidel Castro. El propósito de este artículo es analizar si existió o existe en el socialismo cubano el culto a la personalidad. Para eso, se recurrió a algunas investigaciones realizadas por periodistas, historiadores y escritores; también a los testimonios de distintas personalidades, muchas de ellas ajenas a la política y a la Revolución Cubana, pero que han estado en la isla, conociéndola. Los resultados del artículo señalan que no existen evidencias o pruebas para sostener que el socialismo cubano practicaba o practica el culto a la personalidad; el gobierno desde un inicio no sólo no lo permitía ni lo promovía, sino que lo prohibía y lo combatía. Y que el mismo Fidel Castro, hasta los últimos días de su vida, rechazó que, incluso después de su muerte, se usara su nombre o su imagen con esos fines.
\end{abstract}

Palabras claves: culto a la personalidad, revolución cubana, Fidel Castro, socialismo, pueblo cubano 


\begin{abstract}
Since the triumph of the Cuban Revolution in 1959, its adversaries developed a large literary industry (articles, books and videos) with the aim of attacking, assaulting and defaming it; among the accusations they made, was that in Cuba the cult of Fidel Castro's personality was promoted. The purpose of this article is to analyze if the cult of personality existed or exists in Cuban socialism. For that, it was resorted to some investigations made by journalists, historians and writers; also to the testimonies of different personalities, many of them foreign to politics and the Cuban Revolution, but who have been on the island, knowing it. The results of the article indicate that there is no evidence to sustain that Cuban socialism practiced or practices the cult of personality; the government from the beginning not only did not allow it or promote it, but it also prohibited it and fought against it. And that Fidel Castro himself until the last days of his life, rejected that, even after his death, his name or his image was used for these purposes.
\end{abstract}

Keywords: cult of personality, Cuban revolution, Fidel Castro, socialism, the Cuban people

\section{A manera de introducción}

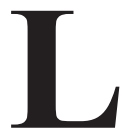
a escalada ideológica desatada contra el triunfo de la Revolución $\mathrm{Cu}-$ bana con el fin de calumniarla, tuvo entre sus blancos principales a la conducción revolucionaria del proceso cubano en la persona de Fidel Castro. Contra Cuba y Fidel Castro se creó una serie de acusaciones, siendo una de ellas que el socialismo cubano promovía el culto a la personalidad. Quienes hacen esos señalamientos nunca han mostrado pruebas de que así fuera. El objetivo de este artículo es mostrar que el culto a la personalidad en la Revolución Cubana no sólo que no se aceptaba, sino que estaba prohibido y la prohibición provenía de los propios dirigentes revolucionarios. El abordaje es relevante, porque se trata de dilucidar un tema que ha sido falsamente vinculado a un dirigente político que condujo un proceso revolucionario con gran influencia en América Latina. Para lograr ese objetivo se recurre a declaraciones, investigaciones y testimonios de distintas personalidades (historiadores, filósofos, sacerdotes, diplomáticos, escritores, cineastas, artistas y políticos). Algunas de las preguntas que se responden en las siguientes páginas son: ¿En qué consiste el culto a la personalidad? ¿El culto a la personalidad que hubo en la ex URSS tuvo su réplica en Cuba? ¿Existió alguna vez culto a la personalidad en Cuba? ¿Promovió la Revolución la adulación al líder cubano?

\section{Fidel Castro, una personalidad} descollante de América Latina

A pocos años del triunfo de la Revolución Cubana (1959), quienes la adversaban construyeron algunas ideas respecto 
a dicho proceso histórico y sus dirigentes, las cuales no coincidían con los hechos; lo hicieron con el propósito de deslegitimar el socialismo cubano como si se tratara de una réplica de la ex Unión de Repúblicas Socialistas Soviéticas (URSS); una de esas ideas fue el culto a la personalidad en relación con Fidel Castro; esta fue aceptada y creída, quedando instalada en el imaginario latinoamericano por mucho tiempo, incluso en los ambientes académicos, hasta el día de hoy.

Desde que Fidel Castro, con veintiún años de edad, apareció en la política en 1947 , cuando cursaba el tercer año de la carrera de derecho en la Universidad de La Habana, se convirtió en un líder, cuya palabra y acción trascendieron rápidamente más allá de Cuba, porque se involucró en la expedición a República Dominicana para exigir la destitución del dictador Rafael Trujillo, y en 1948 estuvo presente en el Bogotazo en Colombia (Blanco, 2011, p. 375-447). De ahí en adelante, por su condición de revolucionario, guerrillero, estadista y su capacidad para sortear la política hostil -el bloqueo económico, comercial y financiero- de once administraciones de los Estados Unidos contra Cuba, hizo que muchos lo vieran como un personaje sui géneris de la historia latinoamericana. Algunos datos llaman la atención -y que no se conoce otro caso similar- y es que se registran más de 638 conspiraciones contra su vida, provenientes de la Agencia Central de Inteligencia (CIA) de los Estados Unidos (Dalband, 2013, p. 2). Otro hecho único es que, según el personal de su despacho presidencial, por lo menos dos mil periodistas de todo el mundo pedían cada año entrevistarse con él (Rodríguez, 2007, p. 5).
De modo que no es un personaje menor o un presidente más de América Latina; es una figura central en la historia del continente, con gran influencia en la política internacional del siglo XX y parte del siglo XXI. Palabras como las del cineasta estadounidense Sydney Pollack -a quien no se le puede imputar de comunista-, expresan algunas dimensiones del entonces dirigente cubano:

Fidel Castro ya no es un personaje real sino que es más grande que la vida misma. Es un líder mundial extremadamente inteligente. Tiene gran valor histórico pues ha sobrevivido a nueve presidentes de Estados Unidos y porque ha estado en contacto con la historia, de una forma que no ha estado nadie que aún viva. La ha hecho, la ha visto y la ha movido. Ha sido parte de ella, la ha empujado. (Bravo, 2001).

Al igual que Pollack, hay cientos de personalidades (diplomáticos, científicos, artistas, políticos, deportistas, religiosos, etc.) que, sin ser socialistas o de izquierda, tienen expresiones semejantes respecto a Fidel. Ese es el caso del pastor evangélico norteamericano Lucius Walker, ajeno a cualquier partido político, que dice: "No hay dudas de que Fidel Castro sigue siendo el primer estadista del planeta. Es un gran hombre y persona generosa de espíritu" (Báez, 2001, p. 117). O lo que expresa el periodista y empresario norteamericano Kirby Jones, distante también de los dogmas políticos:

Fidel Castro es uno de los hombres más encantadores y joviales que cualquiera de nosotros hubiera conocido nunca antes. Esté uno de acuerdo con él o no, 


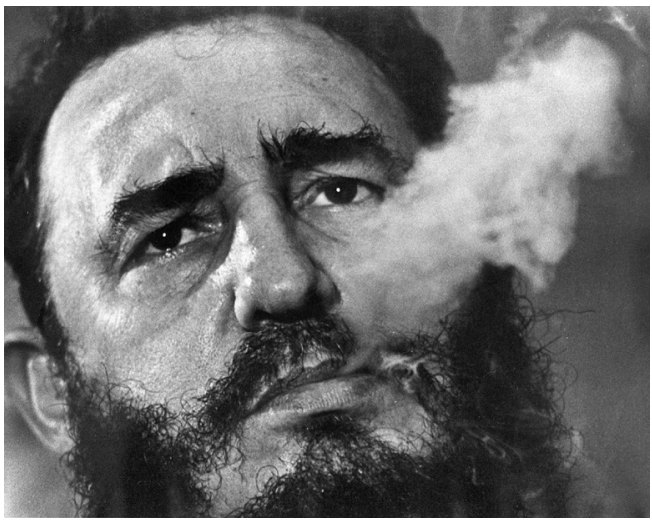

Fidel Castro, en la Habana, 1985 de Charles Tasnadi. https:/elpais.com/elpais/2016/

personalmente Castro es irresistible. Los escritores políticos norteamericanos dirían que se trata de un simple caso de carisma, pero es más que eso. Los dirigentes políticos pueden ser y son carismáticos en su actuación política, pero bastante normales en los momentos privados. Ese no es el caso de Fidel Castro. Sigue siendo una de las pocas personalidades auténticamente electrizantes, en un mundo en que sus colegas parecen insulsos y pedestres (Báez, 2001, p. 112-113)

En 1980, el diplomático Edgardo de Habich, Embajador de Perú en Cuba (19771980), expresaba con estas palabras la impresión que tenía del presidente cubano:

Ahí estaba el Comandante en Jefe de la Revolución Cubana, monstruo, leyenda, mito; el hombre más atacado por el imperialismo, aquel contra quien mayor número de atentados ha perpetrado $\mathrm{y}$ que han sido fallidos acaso solo porque de tanto no temerla, de lo mucho que le ha coqueteado la Muerte ha terminado enamorándose de él y ha decidido conservarlo. Sencillo e imponente, por encima y al margen de vanidades, por primera vez en tres años nos sentamos lado a lado y conversábamos (Báez, 2009, p. 187)

Se trata de un político que, si bien pertenece a un país pequeño del Tercer Mundo, dada su personalidad y el lugar que ocupó en la conducción revolucionaria del proceso cubano, resistiendo los embates del imperialismo, siempre estuvo presente en la política internacional, cuyo quehacer político generó controversias y debates, dentro y fuera de Cuba, entre personas adeptas y personas opuestas a la Revolución; se le odie o se le ame, se le critique o se le alabe, es un personaje singular que traspasa las fronteras de la isla.

Pero sobre la Revolución Cubana y Fidel Castro hay un gran desconocimiento, tanto por la acción desinformadora de sus enemigos -desde que se inició el proceso revolucionario hasta nuestros días-, como por los estereotipos creados por cierta "izquierda" que veía todo como extraordinario. Contra Cuba y su dirigente principal existe una gran industria comercial que ha publicado muchos escritos; tienen autores "especializados", quienes por varias décadas pronosticaron la caída del gobierno socialista y diagnosticaron enfermedades y fechas de muerte de Fidel; son escritores que revelan gran obsesión por él, una especie de odio/ amor, desprecio/admiración. Algunos de ellos califican como publicistas, porque son repetitivos, ruidosos y comerciales; son producciones de imaginerías porque no toman en cuenta la historia ni el contexto y manosean siempre los mismos temas sobre Cuba, cayendo en lo caricaturesco. Los más conocidos en América Latina son Carlos Alberto Montaner (2003), Mario 
Vargas Llosa (2004), Andrés Oppenheimer (2010) y Jorge Castañeda (2016). Ese tipo de publicaciones busca demoler la figura de Fidel Castro, satanizándolo. Para ellos, Fidel personifica todos los males estalinistas. Intentan tergiversar y desfigurar la historia de Cuba y Fidel Castro, para que lo que se sepa y se recuerde de ambos, sea malo, y para que no interesen ni convoquen. Ante tanto odio y desprecio hacia el líder principal de la Revolución Cubana, Gallardo (1999) dice:

Si Fidel Castro fuese encerrado hasta morir en una cárcel norteamericana, muchas personas y pueblos del mundo, y en particular muchos sectores populares de América Latina, lo mantendrían vivo en su memoria y le harían "su" justicia dándole un lugar preferencial en las diversas expresiones de la contra-cultura (p. 12-13).

Fue en la entonces URSS, con Iósif Stalin (1941-1953), en su condición de presidente del Consejo de Ministros soviético, que tuvo su origen la práctica del culto a la personalidad. Esta consistió en la producción de retratos, pinturas, fotografías, monumentos, banderas, pósters, mantas, nombres de ciudades, concursos de retratos, que se hacían con su consentimiento y respaldo; el objetivo era que su imagen se volviera omnipresente y que la gente le rindiera reconocimiento, adulación y devoción. Pero la expresión "culto a la personalidad" se remonta al XX Congreso del Partido Comunista (1956), cuando Nikita Jruschov era presidente del Consejo de Ministros (1953-1964); en este periodo se dio lo que se llamó la "desestalinización" ("acabar" con el culto a la personalidad), que fueron decisiones iniciadas por el XXII Congreso del Partido Comunista (1961), que consistió en modificar la denominación de las ciudades que llevaban el nombre de Stalin; derribar todos sus monumentos y retirar su cuerpo del mausoleo de la Plaza Roja de Moscú, donde reposaba con Lenin. Fidel Castro, en la Habana, 1985 de Charles Tasnadi.

Si en esto consistió el culto a la personalidad en la ex URSS, entonces es necesario ver cómo estas prácticas estuvieron presentes en el gobierno de la isla.

\section{Cuba y el uso de los nombres y los retratos de los líderes}

Uno de los señalamientos sobre el culto a la personalidad, tiene que ver con el uso de los nombres y de los retratos de los líderes, los cuales serían impulsados por el propio gobierno.

En el caso de Cuba, el 20 de marzo de 1959, cuatro meses después del triunfo de la Revolución, el Consejo de Ministros aprobó la ley $\mathrm{N}^{\circ} 174$, la cual prohibía ponerle el nombre de algún dirigente vivo a ninguna calle, a ninguna ciudad, a ningún pueblo, a ninguna fábrica, a ninguna granja; prohibiendo hacer estatuas de los dirigentes vivos; prohibiendo algo más: las fotografías oficiales en las oficinas administrativas. Es decir, desde el principio del proceso revolucionario se previó que quienes estuvieran en el poder usaran indebidamente sus cargos. También se quiso evitar que, por la algarabía y el desborde popular debido al triunfo revolucionario, los dirigentes perdieran la cabeza. Se buscó, con esas medidas, que entendieran, que ellos eran seres humanos igual que todos y que no 
tenían ningún privilegio sobre los demás. El pueblo se sentía identificado con los barbudos que descendieron triunfantes de la Sierra Maestra. Al haber acabado con la sangrienta y criminal dictadura batistiana, la gente avizoraba una nueva etapa de justicia y esperanza para la patria, y hubo que evitar que el pueblo mirara a los dirigentes como semidioses.

Existe un hecho particular que se dio poco después del triunfo de la Revolución; el escultor italiano Enzo Gallo Chiapardi erigió una escultura de Fidel Castro. Apenas Fidel conoció de esta obra, ordenó destruirla (Telesur, 2016).

En 1970, el sacerdote nicaragüenses Ernesto Cardenal visitó por primera vez la Cuba socialista y, en conversaciones con jóvenes poetas críticos del proceso revolucionario, estos le dijeron:

Hay un peligro latente también en la Revolución y es el endiosamiento. El endiosamiento de Fidel. No por culpa de él, sino del pueblo. Él hasta ahora lo ha sabido manejar muy bien, con mucha habilidad, y lo ha mantenido bajo control. Incluso ha señalado ese peligro. Ha dicho que los iniciadores de una Revolución tienen gran prestigio y una autoridad en el pueblo, y que eso puede hacer mucho bien pero también puede hacer mucho mal. Y que hay que esperar que en el futuro ningún dirigente tenga tanta autoridad, porque es peligroso que los hombres tengan tanta autoridad. Ha dicho también: no es necesario estar viendo una estatua en cada esquina, ni el nombre del dirigente en cada pueblo: eso no es crear conciencia en el pueblo, sino fabricar artificialmente una conciencia por medio de consignas y de actos reflejos. Y ha denunciado a los otros países socialistas donde el contacto del pueblo con sus dirigentes es el contacto con las estatuas de los dirigentes del pueblo (Cardenal, 1972, p. 32)

En toda Cuba no existe ninguna estatua de Fidel Castro ni tampoco alguna pintura con su rostro o una escuela o calle que lleve su nombre; el Gobierno no solamente no lo promueve sino que lo prohíbe. Arthur Schlesinger Jr., historiador y asesor especial del Presidente Kennedy, tras una estancia en Cuba en 2001, se refirió a la ausencia del culto a la personalidad en la isla: "Fidel Castro no fomenta el culto a la personalidad. Es difícil encontrar un cartel o incluso una postal de Castro en ningún lugar de La Habana. El ícono de la Revolución de Fidel, visible en todas partes, es el Che Guevara" (Lamrani, 2016, párr. 48).

Al respecto, en conversaciones con Gianni Miná (1988), Fidel le explica lo siguiente:

Tú te encontrarás muy pocos países en el mundo como Cuba, donde los retratos de los dirigentes no están en las oficinas. Cuando por ahí hay un retrato de un dirigente, es porque la gente lo cortó de una revista o se buscó una foto y la puso allí, pero aquí no hay retratos oficiales en las oficinas públicas, desde el principio; siempre hemos estado muy en contra del culto a la personalidad (p.166-167).

Aunque existe esa ley, ésta tampoco puede impedir que muchas familias tengan cuadros de los dirigentes colgados en las salas de sus casas y no puede disuadir a que el pueblo porte las fotos de Fidel, como portan las de José Martí, Ernesto Che 
Guevara, Camilo Cienfuegos o Raúl Castro en las manifestaciones políticas.

Casi dos décadas después de la entrevista con Miná, en 2006, Fidel es entrevistado por Ramonet y éste vuelve a preguntarle por el tema; Fidel le explica:

Yo diría que los medios hablan de mí con respeto, pero con familiaridad. Nadie me ve como una figura encarnada en el Olimpo. Mucha gente me trata como un vecino, conversan conmigo... Por naturaleza, soy hostil a todo lo que pueda parecer un culto a la persona, y usted puede constatar, ya se lo he dicho, que en Cuba no hay una sola escuela, fábrica, hospital o edificio que lleve mi nombre. Ni hay estatuas, ni prácticamente retratos míos. Aquí no se producen retratos oficiales. Es posible que, en alguna oficina, alguien haya puesto una foto mía, pero es una iniciativa personal y en ningún caso se trata de un retrato oficial. Aquí ningún organismo del estado gasta el dinero y pierde el tiempo realizando y repartiendo fotos oficiales mías o de cualquier otro dirigente. Eso en nuestro país no existe...Los que me conocen y conocen mis discursos y mis ideas, saben que soy crítico y autocrítico, y que he combatido con intransigencia toda manifestación del culto a la personalidad o del endiosamiento (2006, p. 609)

Cuando dice que mucha gente lo trata como a un vecino, coincide con Aguilera (2017), quien al referirse a lo que la gente piensa del dirigente cubano, señala: "Hablaban de Fidel como se habla de un vecino al que se admira; no como del jefe del gobierno, el líder del pueblo o títulos por el estilo, sino como de un amigo cercano que se ha ganado la admiración del barrio a fuerza de dar ejemplo" (p. 110).

Gabriel García Márquez, amigo del dirigente cubano, y que solía pasar mucho tiempo en la isla, narra cómo era la relación de Fidel con la gente de a pie:

Cuando habla con la gente de la calle, la conversación recobra la expresividad y la franqueza cruda de los afectos reales. Lo llaman: Fidel. Lo rodean sin riesgos, lo tutean, le discuten, lo contradicen, le reclaman, con un canal de transmisión inmediata por donde circula la verdad a borbotones. Es entonces que se descubre al ser humano insólito, que el resplandor de su propia imagen no deja ver. Este es el Fidel Castro que creo conocer: Un hombre de costumbres austeras e ilusiones insaciables, con una educación formal a la antigua, de palabras cautelosas y modales tenues e incapaz de concebir ninguna idea que no sea descomunal (Cubadebate, 2009, párr. 13)

Hay un dato bastante revelador que contradice lo que señalan sus detractores respecto a la exaltación personal de Fidel Castro; al líder de la Revolución Cubana, en reiteradas ocasiones, distintas editoriales le propusieron inmensas fortunas a cambio de que escribiera sus memorias, pero él siempre las rechazó (Ramonet, 2006, p. 677).

\section{El gobierno colegiado en la Revolución Cubana}

Otro de los señalamientos sobre el culto a la personalidad ha sido que en la isla desde el 1 de enero de 1959 ha existido un gobierno unipersonal, donde Fidel Castro ha tomado decisiones autoritarias, actuando por encima de las instituciones y las leyes. 
La publicidad que se le ha dado a este tema es tan amplia que, incluso en cuatro de las cinco entrevistas más extensas que le han sido realizadas a Fidel, sus entrevistadores abordan con amplitud ese tema: Frei Betto (1985), Gianni Miná (1988), Tomás Borge (1992) e Ignacio Ramonet (2006). Al primero de ellos le explica: "Yo te digo que en este país no se toman jamás, sobre cuestiones importantes, fundamentales, decisiones unipersonales, porque tenemos una dirección colectiva que es donde se analizan y discuten esas cuestiones" (p. 351).

Cuba es una República Socialista cuya soberanía reside en el pueblo, es una democracia popular participativa. El poder es ejercido por medio de la Asamblea del Poder Popular y por otros órganos del Estado. Tiene un Consejo de Estado que es colegiado y ostenta la representación del Estado tanto en el nivel nacional como internacional. El Consejo de Estado es elegido por la Asamblea Nacional del Poder Popular. El Presidente del Consejo de Estado es jefe de Estado y jefe de Gobierno.

En el sistema político cubano, el jefe de Estado tiene menos poder que el que posee un presidente en un sistema presidencialista; en este, él tiene el derecho de iniciar, vetar, promulgar leyes, nombrar ministros, nombrar embajadores, etc., algo que no puede hacer el jefe de Estado en Cuba. En entrevista con el dominico Frei Betto, Fidel le expresa los poderes que posee una figura como el Papa en la Iglesia, y que no las posee el presidente en Cuba:

Incluso pudieran acusar al Papa de dictador, porque el Papa gobierna por decreto, toma decisiones en las designaciones de embajadores, cardenales, obispos, todas son decisiones unipersonales del Papa, y a nadie se le ha ocurrido decir que el Papa es un dictador (1985, p. 346)

Como en todo sistema político moderno, el Presidente dirige un equipo de gobierno; en el caso de Cuba, la dirección central se caracterizó por establecer ciertos principios de responsabilidad compartida y de dirección colectiva; y las decisiones importantes, las decisiones fundamentales se analizan, se discuten y se toman siempre colectivamente.

Quienes afirmaban que en Cuba, había un gobierno unipersonal, sostenían que la Revolución implosionaría, una vez que Fidel Castro dejara la presidencia (desde esa lógica, Fidel se mantenía en la presidencia porque así evitaba que el socialismo cubamo implosionara). En 2008, por razones de salud, Fidel dejó sus cargos públicos y pasaron ocho años en los que él no fue más presidente; sin embargo, no hubo ninguna implosión. Debido a la cantidad de planes para asesinar a Fidel -todos frustrados-, sus enemigos se resignaron a la idea de que la Revolución se derrumbaría definitivamente, una vez que Fidel ya no esté por causas naturales; han pasado dos años de su fallecimiento y los presagios no se han cumplido.

Sobre la creencia de que Fidel quería empoderarse en la presidencia, Ramonet le preguntó en 2006: "¿Usted cree que el relevo se puede pasar sin problema ya?", Fidel le respondió:

De inmediato no habría ningún tipo de problema; y después tampoco. Porque la Revolución no se basa en ideas 
caudillistas, ni en culto a la personalidad. No se concibe en el socialismo a un caudillo, no se concibe tampoco un caudillo en una sociedad moderna, donde la gente haga las cosas únicamente porque tiene confianza ciega en el jefe o porque el jefe se lo pide. La Revolución se basa en principios. Y las ideas que nosotros defendemos son, hace ya tiempo, las ideas de todo el pueblo (2006, p. 692-693)

Contrario a la creencia de que Fidel Castro actuaba con autoritarismo hacia el pueblo cubano, el compositor español Javier Gras expresó en 2001 lo siguiente: "Es admirable como él se ocupa de que su pueblo se enriquezca espiritualmente, que le pida superación, que luche por elevar el nivel cultural de cada cubano. Eso en cualquier otro lugar del mundo es impensable" (Báez, 2001, p. 90). La observación de Gras tiene relación con lo que señala Theotônio Dos Santos, cuando se refiere al nivel intelectual de Fidel:

Si Fidel tiene algo que ver con un dictador, qué buenos serían los dictadores. He conocido a muchos políticos de varias orientaciones, fuera y en el poder. Ninguno tiene o tuvo la profundidad intelectual y la dimensión humana de Fidel Castro. Ninguno logra mantener el estudio sistemático de un problema por horas y horas en todos sus detalles y en todos sus aspectos como Fidel. Ninguno es capaz de mantenerse en una reunión académica por algunas horas, mucho menos por varios días en varias horas diarias (desde las 9 de la mañana hasta las 12 de la noche como lo he visto mantenerse en varias oportunidades). Pero sobre todo es el único político a nivel de jefe de Estado que admite debatir abiertamente con los que divergen de sus puntos de vista. Ciertamente ningún dirigente democrático que conocí tiene esta cualidad. En realidad, es el único que la practica ampliamente, con pasión y rigor, con autenticidad (2006, p. 1)

Al periodista Miná (1988) le había dicho que desde que asumieron la lucha contra el dictador Fulgencio Batista, tuvieron una dirección colectiva y las responsabilidades siempre fueron compartidas:

Desde que empezamos a trabajar, desde los primeros días de la lucha contra Batista, hicimos una pequeña dirección, y a todo lo largo de nuestra historia hubo una dirección colectiva. A pesar de que cuando triunfa la Revolución tenía el mando de un ejército victorioso y una enorme autoridad, un enorme apoyo, yo siempre distribuí la responsabilidad y siempre hice hincapié en que no eran méritos de un hombre, sino de muchos hombres y de todo un pueblo. (p. 167)

El artículo de Gallardo (2006) intitulado adrede "Gracias al Pueblo de Cuba" y publicado a razón de la enfermedad intestinal del dirigente cubano en julio de 2006, es un reconocimiento a la indivisibilidad que existió entre el pueblo cubano y su dirigente; éste no hubiera existido -como guerrillero, revolucionario, estadista e internacionalista- sin el pueblo cubano; no es un hombre el que ha hecho la Revolución, sino todo un pueblo; las entrañas de ese pueblo gestaron a ese dirigente:

Del vientre, discernimiento y corazón de este pueblo complejo y sabio, sufrido y alegre, de su historia, surgió el liderazgo de Fidel Castro. Sin pueblo de Cuba, no hay Fidel. Fidel campeonizó 
con dignidad en todas las batallas porque condensó y expresó a su pueblo. Fidel pudo crecer y convencer fuera de sus fronteras porque, previamente, su pueblo lo había forjado en estatura humana. Pueblo campeón en América Latina el pueblo cubano. Campeón Cuba. Campeón Fidel. Campeones de la dignidad, por primera vez hecha gobierno perdurable, de los más humildes. Viva el pueblo de Cuba. Viva Fidel. Este pueblo y este dirigente nunca morirán si otros pueblos se organizan para que ellos vivan siempre (2006, párr. 4).

\section{Cuba y las elecciones de sus autoridades}

El tercer señalamiento sobre el culto a la personalidad en Cuba tiene que ver con la reelección de sus dirigentes, específicamente con la reelección de Fidel Castro. Lo que se puede leer en los textos producidos por la industria literaria comercial opuesta a la Revolución Cubana es que, en la isla, no hay democracia, se trata de una dictadura y por eso nunca hacen elecciones libres. Este tipo de aseveraciones, incluso es común encontrarlas, como contenido de estudio, en los textos de la materia de Estudios Sociales en los colegios (particularmente en países como Costa Rica), donde los profesores de esa materia evalúan a partir de esas afirmaciones.

Cuba es un país soberano e independiente, y como todo Estado de Derecho tiene su propio Sistema Electoral. Este no es igual al de las democracias occidentales representativas, pero el hecho de que no sea igual -y no tiene por qué serlo- no significa que no sea válido ni que sea menos democrático.
En Cuba, la Ley Electoral No. 72 de 1992 establece dos tipos de elecciones: a) Elecciones generales cada cinco años, donde eligen a los Diputados a la Asamblea Nacional, su Presidente, Vicepresidente y Secretario, así como al Presidente, Primer Vicepresidente, Vicepresidentes, Secretario y demás miembros del Consejo de Estado, a los Delegados a las Asambleas Provinciales y Municipales del Poder Popular y a su vez Presidentes y Vicepresidentes, y b) Elecciones parciales cada dos años y medio, en las que se elige a los Delegados a las Asambleas Municipales del Poder Popular y sus Presidentes y Vicepresidentes (EcuRed, 2018, p.1).

En Cuba, el Presidente no es elegido por voto directo; es la Asamblea Nacional del Poder Popular quien lo elige. Para eso el Presidente atraviesa tres procesos de elección, en el nivel de la Asamblea Municipal, donde se aprueba su candidatura para Diputado; en el nivel de Distrito, donde es electo como Diputado; y en el nivel de Asamblea Nacional, donde los Diputados votan para que sea Presidente del Consejo de Estado y de Ministros. En Cuba, el Partido Comunista no propone, no postula, no promueve ni apoya a ninguno de los candidatos. Es la Asamblea Nacional del Poder Popular quien elige o reelige a sus dirigentes, entre ellos a Fidel Castro. Este sistema electoral no ha sido copiado de otros modelos (Borge, 1992, p. 129-131).

Si se utiliza el criterio que cuando un dirigente es reelegido Presidente o Primer Ministro significa que hay ahí una práctica de culto a la personalidad, entonces ha habido -y todavía hay- culto a la personalidad en varios países llamados democráticos, 


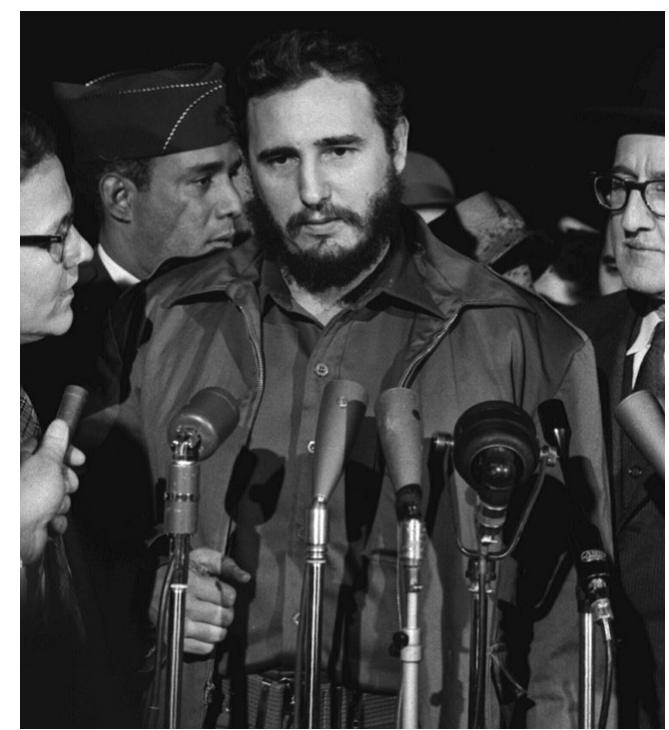

Fidel Castro. Imagen de dominio público CCO.

Tomada de: https://pixabay.com/es/

porque sus dirigentes han sido reelegidos dos, tres o más veces: Margaret Thatcher en Reino Unido de Gran Bretaña (1979, 1983, 1987), François Mitterrand en Francia (1981, 1988), Felipe González en España (1982, 1986, 1989, 1993), Ángela Merkel en Alemania (2005, 2009, 2013), Stephen Joseph Harper en Canadá (2006, 2008, 2011), Aníbal Cavaco en Portugal (2006 y 2011), Barack Obama en los Estados Unidos (2009, 2013), entre otros. Al respecto en una conferencia de prensa en Quito, cuando le preguntaron a Fidel por ese tema, dijo:

Si de eso se trata, de la continuidad de algunos cuadros o de algunos dirigentes en el poder, entonces habrá que hablar de culto a la personalidad en muchos países. Incluso, con todo respeto, podría decir que hay culto a la personalidad en la Iglesia, porque eligen al Papa y el Papa sigue siendo Papa durante mucho tiempo, respetado y venerado (Castro, 1988, p.7).
En 2003, ante la Asamblea Nacional de Cuba, cuando le reeligieron presidente del Consejo de Estado, expresó:

Les prometo que estaré con ustedes si así lo desean mientras tenga conciencia de que pueda ser útil y si antes no lo decide la propia naturaleza, ni un minuto menos, ni un segundo más. Ahora comprendo que mi destino no era venir al mundo para descansar al final de la vida (Castro, 2003, p. 12).

Hay en esas palabras algo de resignación de Fidel para aceptar la relección. Pero era muy difícil para el pueblo cubano, siendo un país sitiado, amenazado y bloqueado por los Estados Unidos, prescindir en esos años, de la dirección de Fidel Castro, con toda la experiencia y conocimientos acumulados. Los enemigos de la Revolución no podían esperar que el pueblo cubano no lo reeligiera constantemente. Ignacio Ramonet indica:

Él tiene algo que lo diferencia de muchos dirigentes políticos, y es que acumula en sí a un teórico de la revolución, a un jefe militar victorioso -que ha ganado varias guerras y posee una estrategia militar- y a un jefe de Estado con una experiencia que no posee ningún jefe de estado ejecutivo (Rodríguez, p. 21).

Dados esos atributos de Fidel, mencionados por Ramonet, la Asamblea Nacional de Cuba siempre tuvo razones para reelegirlo. Volodia Teitelboim, intelectual y político chileno, indica: "Nunca vi un hombre más grande, más profundo, más inteligente, más de principio. Lo digo en todas partes, si los Estados Unidos tuvieran un presidente el diez por ciento 
de Fidel, sería un gran país democrático" (Báez, 2001, p. 186).

\section{El pueblo cubano y su relación con Fidel Castro}

La literatura que circula respecto al culto a la personalidad en Cuba, difunde también la idea de que las autoridades cubanas obligan al pueblo a rendirle pleitesía a Fidel Castro. Se parte de la premisa que la identificación del pueblo con él no es sincera sino forzada. Esta idea, al igual que las anteriores, se ha repetido bastante; incluso, a propósito de las honras fúnebres de Fidel en noviembre y diciembre de 2016, la gran prensa comercial señalaba, que la Seguridad del Estado había obligado a las familias cubanas a despedir los restos (cenizas) de Fidel por cada ciudad donde pasara.

El propio director y productor de cine, el estadounidense norteamericano Oliver Stone, muestra en su documental Looking for Fidel (2004) preocupación por el tema. Con el fin de comprobar cómo la policía cubana obligaba al pueblo a acuerpar y rendir culto a Fidel, él reta a Fidel a ir de forma improvisada a cualquier lugar para ver la reacción de la gente y la participación de la Seguridad del Estado; Fidel le pide que escoja él a dónde quiere ir. En el documental se puede ver que ambos llegan sorpresivamente a un barrio de La Habana Vieja; al enterarse la gente de la presencia de Fidel, salen espontáneamente de sus casas, y de pronto una gran multitud se aglomera alrededor de Fidel, todos quieren saludarle, darle la mano y abrazarle; enseguida empiezan a corear ¡Fidel! ¡Fidel ¡Fidel! Oliver Stone se queda perplejo porque no entiende lo que está viendo, $\mathrm{y}$ en ninguna parte hay miembros de la Seguridad del Estado obligando a la gente a que se acerquen a saludar a Fidel.

El periodista cubano Luis Ortega, que luego del triunfo de la Revolución se fue a vivir a Miami (no puede decirse que es un simpatizante o defensor del líder cubano), expresó en una entrevista:

Fidel Castro ya ha rebasado la historia, ya es invulnerable. Es una leyenda de tiempos fabulosos. Eso es un mito. Mucha gente quiere tocarlo para ver si es real. Cuando él se desliza por un pasillo, lentamente, midiendo sus pasos, un poco a cámara lenta, como suelen siempre caminar los mitos, no es que esté enfermo o que le duela nada es que lleva ya sobre los hombros una carga tan grande de historia que ha tenido que renunciar a la agilidad de los primeros años (Báez, 2001, p. 19).

Para el político y primer ministro de Jamaica Percival J. Patterson, "ni siquiera los detractores de Fidel pueden poner en tela de juicio su sinceridad, su sabiduría intelectual, sus capacidades de orador y su carisma personal" (Báez, 2001, p. 146).

Los publicistas han llegado a decir que la seguridad cubana vigilaba y exigía la participación de la gente en los actos públicos. Si eso hubiera sido cierto, entonces, cada vez que la Plaza de la Revolución albergó a un millón de manifestantes, la mitad de ellos fueron de la Seguridad del Estado o detrás de ellos hubo otro millón que pertenecían a la Seguridad del Estado que los estaban vigilando. ¿Será que en todas las marchas de cientos de 
miles de cubanos por el Malecón de La Habana desde 1959, también han desfilado cientos de miles de la policía cubana supervisándolos? En 2000, toda la isla se movilizó para exigir el retorno del niño Elián González secuestrado en los Estados Unidos por la mafia cubanoamericana de Miami, esto fue noticia internacional y tuvo cobertura mundial por los medios televisivos, ¿también habrán estado ahí los miembros de la Seguridad del Estado pasando lista para saber quiénes se ausentaban para reprimirlos?

El 5 de agosto de 1995, en pleno periodo especial, el pueblo cubano realizó una marcha por el primer aniversario del fracaso del mayor disturbio sucedido en La Habana. Cientos de miles de personas marchaban por el Malecón, y una de las consignas que vitoreaban era: " $\mathrm{Pa}$ ' lo que sea Fidel pa' lo que sea”. Al preguntársele a una señora cómo era posible que con tantas dificultades y carencias en la isla, ella repitiera con gran entusiasmo esa consigna, ella respondió que a pesar de la crisis, en Cuba no se había cerrado ninguna escuela, ni ningún centro médico y a los niños no les faltaba leche un solo día: "Si usted nos da un hombre que haga lo mismo que hizo Fidel al frente del gobierno, hoy estaría yo aquí coreando su nombre." Un conocedor de la realidad de la isla es el pintor ecuatoriano Oswaldo Guayasamín, quien afirmaba que "El pueblo está al lado de Fidel de una forma absoluta, el pueblo de Cuba dice que ojalá Fidel sea eterno" (Báez, 2001, p. 143).

¿Qué responsabilidad pudo tener Fidel Castro de haber sido un hombre carismático, amado por su pueblo y querido por otros pueblos del mundo? Esta situación, de simpatía espontánea y natural por parte del pueblo hacia él, nada tiene que ver con el culto a la personalidad. Julio Cortázar lo expresó así:

Fidel es un hombre que plasma la revolución en sí misma como tal: como dirección, orientación, fisonomía. Es evidente que para el conjunto del pueblo cubano, al margen de sus cualidades, de su eficacia como dirigente, es ya un símbolo que adquiere un valor fuera de lo humano, fuera de lo cotidiano. Cuando se oye la palabra de Fidel en la boca de un niño, de un adulto, además del valor directo, tiene una serie de resonancias como la música de armónica que toca las fibras de la sensibilidad, de la conciencia. Fidel es el escultor de la Revolución cubana (Báez, 2001, p. 111).

Ernesto Cardenal, en su libro de memorias a raíz de su vista a Cuba, registra innumerables experiencias que vivió y otras que escuchó de los propios protagonistas. La siguiente anécdota se refiere a una de las visitas de Fidel a la Sierra Maestra y retrata la horizontalidad que el líder de la Revolución tenía con el campesinado; un estilo de vida por demás opuesto al culto a la personalidad:

¡Cómo se emocionó cuando volvió! Y era graciosísimo ver la confianza con que lo trataban los campesinos. Se le colgaban unos viejos desdentados. "Caballo, tú no cumples ná." Porque así le dicen: Caballo. "Tú dijiste que la escuela iba a ser aquí y mira la hicieron allá. Caballo, tú prometes y no cumples, tú no cumples ná, Caballo." Y a él le daba mucha risa (1972, p. 74-75). 


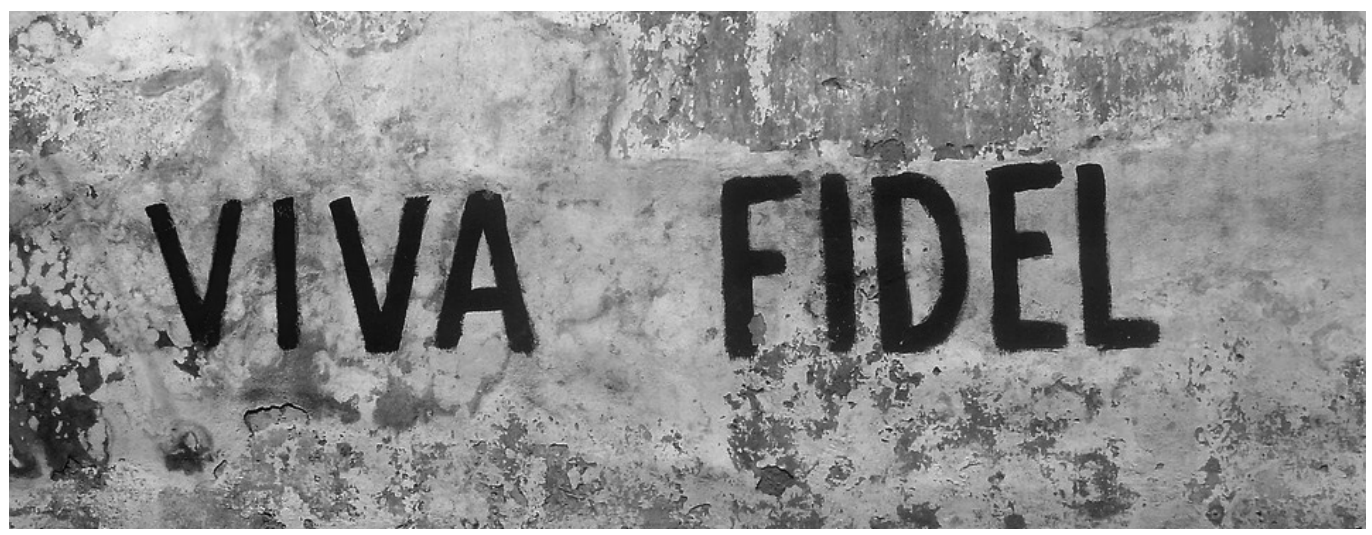

Fidel Castro, una vida en imágenes. El País, 28 noviembre, 2016.

Tomada de: https:/elpais.com/elpais/2016/

Fidel no fue un burócrata de la Revolución; desde el triunfo en 1959, condujo un proyecto político para que Cuba y el pueblo tuvieran dignidad, independencia, soberanía y derechos. A pesar de todo tipo de agresiones por parte de los Estados Unidos contra Cuba, la Revolución logró indiscutibles transformaciones que beneficiaron al pueblo en áreas como la seguridad, la educación, la salud, la cultura, el deporte, las artes, la esperanza de vida, la baja mortalidad infantil, etc. Y como si eso no fuera suficiente, Cuba convirtió el internacionalismo solidario en la insignia ética del socialismo; no hicieron la Revolución pensando sólo en ellos. Por eso Mario Benedetti, a quien no se le puede señalar de construir fetiches, expresó que "los pueblos siempre han reconocido en el líder cubano su obsesión por la justicia, por la autodeterminación, por la soberanía de cada nación, pero también por la solidaridad con otros pueblos" (Báez, 2001, p. 125).

Han despilfarrado grandes sumas de dinero sembrando la idea que en Cuba existe el culto a la personalidad -una especie de estalinización caribeña- hacia Fidel
Castro, pero no han podido probarlo. No se ha querido entender ni aceptar que lo que ha habido en Cuba, y más allá de ella, es el reconocimiento a la dignidad de una personalidad latinoamericana. El escritor Eduardo Galeano dijo que "Fidel Castro es un símbolo de dignidad nacional. Para los latinoamericanos, que ya estamos cumpliendo cinco siglos de humillación, un símbolo entrañable" (Galeano, 1992, p. 88). En opinión de Alicia Alonso, una de las figuras más relevantes en la historia de la danza y figura cimera del ballet clásico mundial:

Él no es local. Él es parte de la historia. No sólo de nuestra historia, sino de la historia de la humanidad. Pienso que es tan grande que se convierte en una partecita, en una cosa sencilla. Si sintiera lo grande que es, lo mataría el peso (Báez, 2001, p.20).

Fidel Castro, como marxista que fue, siempre afirmó que las revoluciones y las grandes transformaciones las hacen los pueblos: "con las masas todo, sin las masas nada." Aunque esto es cierto, sin embargo, debido a la particularidad de su caso, como 
estadista y revolucionario que fue, cada vez más se tendrá que apreciar el papel de la personalidad en la historia, que nada tiene que ver con el culto a la personalidad. Fidel Castro es una personalidad que luchó arropado de dignidad y de pueblo, y que pocas veces aparecen en la historia.

El reconocimiento a la resistencia, la dignidad, la lucha, la independencia y la esperanza que significó Fidel, lo explica Salim Lamrani así:

Es realmente un personaje fascinante, digno de admiración y respeto; un patriota de la más pura especie, que siempre se ha negado a doblar el espinazo frente a los poderosos. Permanece fiel a sus principios a pesar de la adversidad, pues está profundamente convencido de la extraordinaria fuerza de las ideas. Fidel sigue creyendo que otro mundo, menos cruel, es posible. Por eso es un símbolo de dignidad y de esperanza no solo para los cubanos, para la humanidad entera (Báez, 2009, p.219).

\section{La invariabilidad de Fidel hasta las últimas horas de su vida}

Si hubo alguna persona en Cuba a quien se le dieron todos los reconocimientos como una figura extraordinaria, fue a Ernesto Guevara (a quien hoy en diferentes partes del mundo algunos lo veneran como un santo) $\mathrm{y}$, ese reconocimiento fue hecho desde las altas esferas del poder, por el propio Fidel, pero eso se hizo después de que cayó en combate (si se le hubiera hecho algún tipo de evocación cuando estuvo vivo, seguro que el Che lo hubiera rechazado, porque él era distante a todo eso). Si fuera cierto que Fidel promovía el culto a la personalidad -como le acusaban sus enemigos-, llama la atención que él no buscara ningún tipo de gloria, y que le solicitara al pueblo cubano, el 18 de octubre de 1967 en la velada solemne en memoria del Comandante Guevara, lo siguiente:

Si queremos expresar cómo aspiramos que sean nuestros combatientes revolucionarios, nuestros militantes, nuestros hombres, debemos decir sin vacilación de ninguna índole: iQue sean como el Che! Si queremos expresar cómo queremos que sean los hombres de las futuras generaciones, debemos decir: ¡Que sean como el Che! Si queremos decir cómo deseamos que se eduquen nuestros niños, debemos decir sin vacilación: ¡Queremos que se eduquen en el espíritu del Che! Si queremos un modelo de hombre, un modelo de hombre que no pertenece a este tiempo, un modelo de hombre que pertenece al futuro, ¡de corazón digo que ese modelo sin una sola mancha en su conducta, sin una sola mancha en su actitud, sin una sola mancha en su actuación, ese modelo es el Che! Si queremos expresar cómo deseamos que sean nuestros hijos, debemos decir con todo el corazón de vehementes revolucionarios: ¡Queremos que sean como el Che! (Bohemia, 2017, párr.23).

“¡Seremos como el Che!”, es el lema que repiten los niños pioneros cubanos; se trata de un juramento que deberán hacer suyo cuando le aten al pecho la pañoleta azul. Todo esto se hace desde 1968 como muestra del espíritu internacionalista de las más jóvenes generaciones y el deseo expresado por Fidel Castro de que la figura del Che Guevara fuera ejemplo que seguir por niños y adolescentes. Es muy contradictorio 
entonces que, si Fidel buscaba que le rindieran culto a él, pidiera que los niños fueran como el Che.

Otra muestra de la renuncia de Fidel a cualquier tipo de pleitesía, ya no sólo en vida, sino para después de muerto, la solicitó él mismo. El 3 de diciembre de 2016, en el discurso pronunciado por el presidente Raúl Castro Ruz, en el acto político en homenaje póstumo a Fidel, en la Plaza Mayor General Antonio Maceo Grajales, de Santiago de Cuba, expresó el siguiente deseo de su hermano:

Fiel a la ética martiana de que "toda la gloria del mundo cabe en un grano de maíz", el líder de la Revolución rechazaba cualquier manifestación de culto a la personalidad y fue consecuente con esa actitud hasta las últimas hora de vida, insistiendo en que, una vez fallecido, su nombre y su figura nunca fueran utilizados para denominar instituciones, plazas, parques, avenidas, calles u otros sitios públicos, ni erigir en su memoria monumentos, bustos, estatuas y otras formas similares de tributo (Granma, 2016. p. 1).

E1 27 de diciembre de 2016, la Asamblea Nacional de Cuba (Parlamento) aprobó una ley que prohíbe utilizar el nombre de Fidel Castro para nombrar lugares públicos o construir monumentos a su memoria. El texto indica que se prohíbe expresamente el empleo del nombre de Fidel "para denominar instituciones, plazas, parques, avenidas, calles y otros lugares públicos, así como cualquier tipo de condecoración, reconocimiento o título honorífico". También quedó prohibida la utilización de su figura "para erigir monumentos, bustos, estatuas, tarjas conmemorativas y otras formas similares de homenaje", en sitios públicos (Cubadebate, 2016). En Cuba, tampoco se han emitido nunca sellos de correos ni monedas que esculpieran el rostro de Fidel.

A diferencia de lo que han hecho en otros países, una vez que fallecieron sus líderes comunistas, en Cuba tampoco existe un mausoleo con el cuerpo de Fidel, donde la gente pueda rendirle tributo. Cuando Raúl Castro anunció su muerte dijo que "de acuerdo a la voluntad expresa del compañero Fidel", éste sería cremado. Probablemente esa decisión tenía que ver con su renuencia a ser honrado con un mausoleo. Hay varios ejemplos de cómo el culto a la personalidad se perpetúa una vez que los personajes han muerto. Uno de ellos es el Mausoleo de Vladimir Lenin -la Tumba de Lenin- situado en la Plaza Roja de Moscú, donde se expone su cuerpo embalsamado desde su muerte en 1924 (el gobierno soviético ordenó su construcción). También está el Mausoleo de Mao Zedong, en la Plaza de Tiananmen, en Pekín, donde se encuentra el cuerpo embalsamado del que fuera presidente del Partido Comunista de China desde 1943 hasta su muerte en 1976. También los restos del líder del Partido Comunista de Vietnam, Ho Chi Minh, están expuestos en un memorial en Hanoi. Y los cuerpos de los líderes de Corea del Norte, Kim Il Sung y Kim Jong Il, se encuentran en el mausoleo conocido como el Palacio del Sol de Kumsusan. Pero en ninguna parte de Cuba existe un mausoleo de Fidel Castro. Para Enrique Ubieta (2017), a Fidel hay que encontrarlo en la conciencia del pueblo cubano: 
Fidel no se va. Por propia decisión, no estará en los monumentos de mármol de las ciudades del país que refundó, no será un nombre en una avenida, una escuela o un hospital, a los que se consagró. Que nadie venga a buscarlo en las piedras, sino en las conciencias. Será el aire que respiramos los cubanos, el espíritu de lucha que nos inspirará...Fidel es Cuba, porque todos somos Fidel. Ese es el mensaje que los cubanos gritamos a pleno pulmón, con el puño en alto, para que el mundo lo sepa (p. 101).

\section{Conclusiones}

Las acusaciones que han hecho los adversarios de la Revolución Cubana, que la señalan de promover, obligar y desarrollar el culto a la personalidad de Fidel Castro, carece de fundamentos y pruebas; por el contrario, existen evidencias -por ejemplo la ley- que desde el inicio de la Revolución, la dirigencia política previó y prohibió cualquier indicio de esa práctica. El propio gobierno siempre fue crítico y tajante contra el culto a la personalidad, actitud que mantuvo el propio Fidel Castro hasta las horas previas de su muerte.

Quienes sostienen que en Cuba no existe el culto a la personalidad no son solamente las autoridades o el pueblo cubano, sino muchas personas (cineastas, artistas, diplomáticos, políticos, escritores) provenientes de distintos países; se trata de expresiones que se sustentan en haber estado en Cuba en varias ocasiones y haberla recorrido; y muchos de ellos no tienen ninguna vinculación política con la Revolución Cubana ni con ningún partido de izquierda en sus países.
Lo que se puede comprobar es que el pueblo cubano, a lo largo de varias generaciones, ha desarrollado una relación muy estrecha con la dirigencia revolucionaria, y que, de manera especial, expresa respeto, admiración, elogios, solidaridad y compromiso por Fidel Castro, a quien visualizan y sienten como uno más de ellos. No sólo el pueblo cubano sino también los visitantes se refieren a él como un hombre culto, carismático, inteligente, sencillo, humanista, democrático, teórico de la revolución, estratega militar, estadista, símbolo de resistencia, electrizante, digno, fascinante, entre otros; todos estos epítetos son espontáneos y nada tienen que ver con el culto a la personalidad.

Si bien es cierto que en la antigua ex URSS existió el culto a la personalidad y fue promovido por el propio gobierno encabezado por Stalin, la realidad del socialismo cubano fue completamente distinta; la Revolución Cubana no sólo no la admitió sino que la combatió por iniciativa y acción del propio Fidel Castro.

\section{Referencias}

Aguilera, A. (2017). Un gigante de verde olivo. Revista Casa de las Américas. ( $\left.\mathrm{N}^{\circ} 286\right)$, enero-marzo, 110-111.

Báez, L. (2001). Absuelto por la historia. La Habana, Cuba: Editorial de Ciencias Sociales.

Báez, L. (2009). Así es Fidel. La Habana Cuba: Casa Editora Abril.

Betto, F. (1985). Fidel y la religión. La Habana, Cuba: Oficina de Publicaciones del Consejo de Estado. 
Blanco, K. (2011). Fidel Castro Ruz. Guerrillero del Tiempo. Conversaciones con el líder de la Revolución Cubana. Tomo I. La Habana, Cuba: Casa Editora Abril.

Bohemia (2017). ¿Que sean como el Che! Recuperado de http:// bohemia.cu/historia/2017/09/ que-sean-como-el-che/

Borge, T. (1992). Fidel Castro. Un grano de maíz. La Habana, Cuba: Oficina de Publicaciones del Consejo de Estado.

Bravo, E. (Productora). (2001). Fidel (La historia no contada). [Video]. Estados Unidos.

Cardenal, E. (1972). En Cuba. Bogotá, Colombia: Carlos Lohlé.

Castañeda, J. (2016, 18 de agosto). Y en eso llegó Fidel. Recuperado de http://www. milenio.com/opinion/jorge-castaneda/ amarres/y-en-eso-llego-fidel

Castro, F. (1988). Una América Latina más unida. Conferencia de prensa en Quito. La Habana, Cuba: Editora Política.

Castro, F. (2003). Discurso pronunciado por el Presidente de la República de Cuba Fidel Castro Ruz, sobre la actual crisis mundial, al tomar posesión de su cargo. Recuperado de http://www.cuba.cu/gobierno/discursos/2003/esp/f060303e.html

Cubadebate (2016). Aprueba el Parlamento ley sobre el uso del nombre y la figura de Fidel Castro Ruz. Recuperado de http://www.cubadebate. cu/noticias/2016/12/27/presentanproyecto-de-ley-sobre-el-uso-delnombre-y-la-figura-del-companerofidel-castro-ruz/\#.Wz5tOzknY10
Dalband, H. (2013). La obsesión de la CIA por asesinar a Fidel Castro: el fracaso estadounidense. Recuperado de http://www.rebelion.org/noticia. php?id=170802

Dos Santos, T. (2006, 11 de agosto). Fidel Castro: Un testimonio. Granma, p. 1.

EcuRed (2018). Sistema electoral cubano. Recuperado de https://www.ecured. $\mathrm{cu} /$ Sistema_electoral_cubano

Galeano, E. (1992). Ser como ellos y otros artículos. México, D. F.: Siglo XXI Editores.

Gallardo, H. (1999). Castro/Pinochet. San José, Costa Rica: Ediciones Perro Azul.

Gallardo, H. (2006). Gracias al Pueblo de Cuba. Recuperado de http:// heliogallardo-americalatina.info/ index.php?option $=$ com_content $\&$ view $=$ article $\&$ id $=21 \&$ catid $=8 \% 3 \mathrm{~A}$ en-periodicos $\&$ Itemid $=103$

García, G. (2009). El Fidel Castro que yo conozco. Recuperado de http://www.cubadebate.cu/opinion/2009/08/13/gabriel-garciamarquez-el-fidel-castro-que-yo-conozco/\#.W06zJDknY10

Granma. (2016) Discurso integro del General de Ejército Raúl Castro Ruz en el acto de masas en homenaje póstumo al Comandante en Jefe Fidel. Recuperado de http:// www.granma.cu/hasta-la-victoria-siempre-fidel/2016-11-30/ discurso-integro-del-general-deejercito-raul-castro-ruz-en-elacto-de-masas-en-homenaje-postumo-al-comandante-en-jefe-fidel-30-11-2016-02-11-56 
Lamrani, S. (2016). 50 verdades sobre Fidel Castro. Recuperado de http://www.cubadebate.cu/ especiales/2016/08/07/50-verdades-sobre-fidel-castro/\#. Wzq7UjknY10

Miná, G. (1988). Un encuentro con Fidel. La Habana, Cuba: Oficina de Publicaciones del Consejo de Estado.

Montaner, C. (2003, 7 de mayo). Deconstruyendo a Fidel. Recuperado de https://www.cadal.org/documentos/ nota.asp?id nota $=4916$

Oppenheimer, A (2010, 16 de agosto). La jugada de Fidel Castro. Recuperado de http://todopolitica.foroactivo. com/t3606-la-jugada-de-fidel-castro-por-andres-oppenheimer

Ramonet, I. (2006). Cien horas con Fidel. La Habana, Cuba: Oficina de Publicaciones del Consejo de Estado.
Rodríguez, A. (2007). Los afortunados entrevistadores de Fidel. La Habana, Cuba: Oficina de Publicaciones del Consejo de Estado.

Stone, O. (Productor). (2004). Looking for Fidel. [Video]. Estados Unidos.

Telesur (2016). ¿Por qué Fidel Castro no quería ninguna estatua con su figura? Recuperado de https://www. telesurtv.net/news/Por-que-FidelCastro-no-queria-ninguna-estatuacon-su-figura-20161228-0048.html

Ubieta, E. (2017). Yo soy Fidel. Revista Casa de las Américas. ( $\mathrm{N}^{\circ}$ 286), enero-marzo, 99-101.

Vargas, M. (2004, 31 de octubre). Las "putas tristes" de Fidel. Recuperado de https:/elpais.com/diario/2004/10/31/ opinion/1099173606_850215.html 
